\title{
The pattern of infections among under-fives: a call for actions
}

By Leshabari Kelvin MD4 2006/07

Ramji Radhika MD2 2006/07

\begin{abstract}
INTRODUCTION

Infectious diseases are by far the most frustrating challenges in the health systems of most tropical nations. Unlike other challenges, infections have their causes known and solutions at hand. Paediatric world is the most important victim of infectious ailments. Various models, interventions for reduction/elimination of infectious diseases have been put forth but the strategies (in most tropical nations) have not bore the anticipated fruits.
\end{abstract}

\section{OBJECTIVES}

To assess the pattern of infections and its association with nutritional status among under-five years population of Dodoma in August - September 2007.

\section{METHODOLOGY}

A descriptive, cross-sectional community based study was done at Makulu ward of Dodoma district involving 396 under five year population derived from 322 different families. Data was collected using a standard structured questionnaire and analysed using epi-info 6 software.

\section{RESULTS}

Among 396 children studied, 52.3\% were females. Maximum representation was found in the age range of 12-23 months (mode at age of 14.0 months). More than half (50.8\%) of all children surveyed were found to have fever (at the time of the survey) and $58.8 \%$ were reported to have had fever within a period of 1 month prior to conduction of the study. Among children with fever, $52.3 \%$ had a normal weight to age ratio. More than $90 \%$ of surveyed children were reported to have been weaned before 6 months of age.

\section{CONCLUSION}

The prevalence of fever was found to be high (reflecting infectious nature) in this study.

\section{RECOMMENDATIONS}

More analytical studies are needed in this area to explain for the nature and causes of fever in this age group at Makulu ward.

\section{INTRODUCTION}

Infectious diseases in the developing world far outweigh other factors in morbidity and mortality statistics. While causes for these infectious diseases are known and therapeutic and preventive ways at hand, still more people are dying especially among the young generation in the tropics because of infectious diseases than wars (a single serious rival to humans in the tropics!) According to World Health Organisation (WHO), majority of dying patients from infectious diseases (i.e. 90\%) are due to only a handful of agents. This can be evidenced by the fact that only six (6) infectious diseases account for more than half of all deaths in children 1 .

The deaths toll from infectious diseases statistics is just part of the tragedy. At individual level for instance, the pain inflicted by consequences of infectious ailments is quite extreme (death, disabilities, social unrest). While for example measles alone causes severe disabilities (deafness, lung and brain damage) among under-five children; those who survive are prone to other infectious ailments that will make the rest of their lives in jeopardy starting at late adolescence or early adulthood. These encompass diseases like lymphatic filariasis that is by far claimed to be second to mental illness as the leading cause of long-term disabilities in developing countries1.

The most frustrating challenge behind infectious diseases lies on the fact that the consequences of morbidity and mortality indices due to infectious 
diseases are multiple as not only the health sector is affected but also other cadres. It is no longer news that production process in developing countries has been deteriorating over years now due to ailments workers suffer (e.g. HIV/AIDS, malaria). So while interventions put forth so far rely most on the ability of the health sector to act, the move is unlikely to bring the anticipated results. It is therefore believed that interventions that are multi-systemic can be effective in combating the tragedy.

Majority of interventions that may be beneficial to health challenges of tropical world should be evidence-based. It is on this basis, this article finds its roots from a survey done in Dodoma (the capital city of Tanzania) on nutritional status of under-fives and its associated factors. Thus, results of some of the study objectives form the pivot of this article. Specifically the article describes the association between the pattern of fever (as a marker of infections) and nutritional status of pre-school aged children of Dodoma.

\section{METHODS}

A cross-sectional, community based survey was conducted at Makulu ward of Dodoma district (the urban zone of the capital city of Tanzania) between August and September 2007. The overall aim of the study was to assess the nutritional status of underfive year old children and their associated factors.

Specifically, this article yields findings on the association between nutritional status and infections among under-fives of Dodoma district.

Children under-five years of age were the target population in this survey. Thus they ranged from neonates to toddlers (age range: 1 day to 59 months).

Stratified sampling was the main sampling method used; where by representative wards were obtained from a list of all wards in Dodoma district. From the ward level, strata were made (among streets and households) to get the representative number of households. The selected households were furthermore visited to include all under-fives living under one roof; whose parents/guardians were consented for participation in this study. Thus all children found in the selected localities had an equal chance of being recruited in the study.

Inclusion criteria for this survey included all those under-fives whose parents/guardians were residents of Makulu ward. Residency was defined from parents/guardians who were either permanent local (residents since birth) or those who have stayed at Makulu ward for at least 6 months consecutively prior to the survey period.

For the under-five to be included at least one parent/guardian was to be present at the time of the survey. Therefore, all under-five years old children whose either parent/guardian was not found at the time of the 1st visit were followed up at least thrice in different times and days before declared non-respondents.

This study managed to recruit 396 under-five year children that originated from a total of 322 households visited during the survey. The sample size was calculated from the formula designed by Armitage and Berry in which the proportion of those malnourished (in that community) was estimated to be $50 \%$. Thus a minimal sample size number of 384 children were deemed mandatory to give the study its intended power.

A standard structured Swahili questionnaire was made from the original English version; that was used as the main research tool in the study, with different sections.

Data were coded into a computer (whose template was made earlier) and then cleaned for errors. Analysis followed and was done using epi-info 6 statistical software. Statistical significance tests included the usage of P-values to assess for the role of chance and X2 (Chi-square) test to account for the association between different variables. In this study, P-values $<0.05$ were used to disprove the null hypothesis.

Anthropometric measurements included in this survey were the weight, height and Mid-Upper Arm Circumference (MUAC). These were then used in determining weight for age, weight for height and height for age. Values below normal were considered to show the degree of underweight, wasting and stunted respectively. The study also assessed the pattern of fever among the study sample.

Ethical clearance for the study was obtained from MUCHS Directorate of Research \& Publication via dept. of community health, SPHSS. Permission to conduct the study at Makulu ward of Dodoma was obtained from the local government authorities of Dodoma and a verbal informed consent was 
sought to heads of all households visited before interview schedules using the assistance of village leaders.

\section{RESULTS}

We surveyed a total of 396 under-five years of age children. Among these, 206 (52\%) were females. Most $(81.7 \%)$ of all surveyed under-fives were toddlers (see table no. 1 below)

TABLE 1: DISTRIBUTION OF SURVEYED UNDERFIVES BY AGE AND SEX

\begin{tabular}{|l|r|r|r|}
\hline $\begin{array}{l}\text { AGE GROUP } \\
\text { (MONTHS) }\end{array}$ & MALE & FEMALE & TOTAL \\
\hline $0-5$ & 7 & 14 & 21 \\
\hline $6-11$ & 28 & 26 & 54 \\
\hline $12-23$ & 76 & 86 & 162 \\
\hline $24-35$ & 28 & 31 & 59 \\
\hline $36-47$ & 25 & 29 & 54 \\
\hline $48-59$ & 26 & 20 & 46 \\
\hline Total & 190 & 206 & 396 \\
\hline
\end{tabular}

(Note: Mode age was 14.0 months, Male: female $=1: 1.01$.)

Another important finding from our survey was the observation that more than half (51.8\%) of the study sample was found to have fever (at the time of the survey). The figure increased significantly (to 58.8\%) when an inquiry of fever status within one (1) month prior to execution of the study was made (refer figure no.1 below).

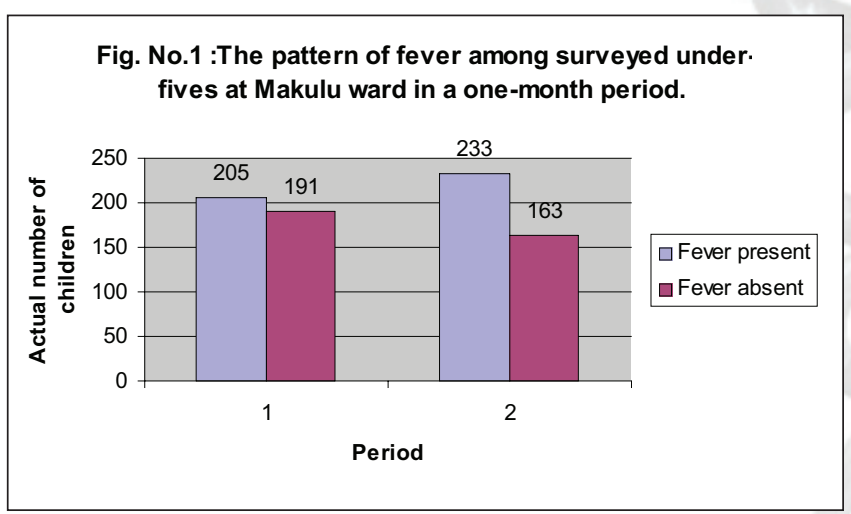

Note: The total number of children whose fever status were identified $=396$. Numbers in blocks (above) refer to actual frequency.

While blocks in no. 1 refers to the pattern of fever at the time of the survey, blocks in no. 2 refers to the pattern of fever within a one-month period from the time of the survey assessed verbally.

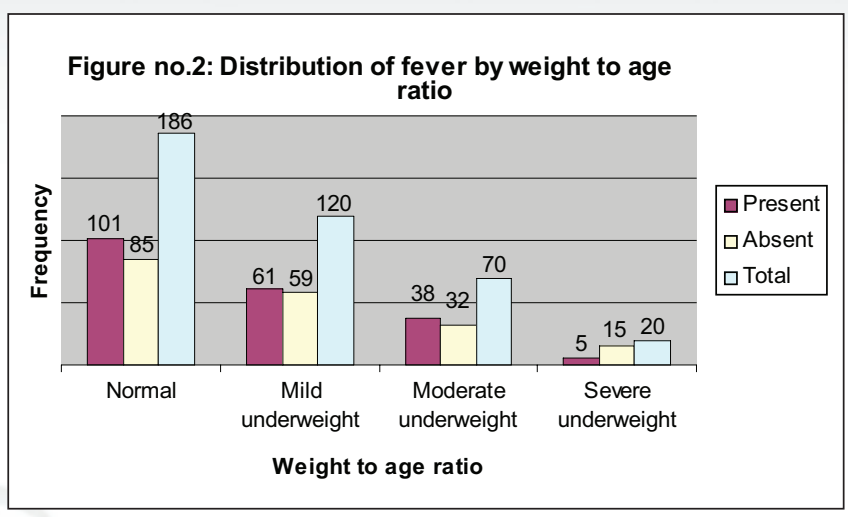

Note: $\mathrm{P}$-value $<0.01, \mathrm{X}^{2}$ result $=29.56, \mathrm{df}=5$, total number of surveyed children $=396$

Also from this study (refer figure no.2), almost half (49.3\%) of all under-fives who had fever (in the set time scale) were found to have a normal weight to age ratio.

Of paramount importance in this survey, was the association observed between the level of education of the caretaker and the pattern of fever among under-fives as seen in table no.2 below;

\section{TABLE 2: THE PATTERN OF FEVER BY LEVEL OF EDUCATION OF THE CARETAKER}

\begin{tabular}{|l|c|c|c|}
\hline \multirow{2}{*}{$\begin{array}{l}\text { LEVEL OF } \\
\text { EDUCATION }\end{array}$} & FEVER & FEVER & TOTAL \\
OF CARETAKER & PRESENT & ABSENT & \\
\cline { 2 - 4 } No formal education & 61 & 20 & 81 \\
\hline $\begin{array}{l}\text { Incomplete } \\
\text { primary education }\end{array}$ & 47 & 21 & 68 \\
\hline $\begin{array}{l}\text { Completed } \\
\text { primary education }\end{array}$ & 82 & 108 & 190 \\
\hline Secondary education & 15 & 40 & 55 \\
\hline Tertiary education & 0 & 2 & 2 \\
\hline Total & 205 & 191 & 396 \\
\hline
\end{tabular}

Note: $\mathrm{P}$-value $=0.0000, \mathrm{X}^{2}$ test figure $=22.67$, $\mathrm{df}=3$

From above, 61 (75.31\%) of children under the jurisdiction of caretakers with no formal education were found to have fever in the set time period as compared to none among caretakers with tertiary education.

Also, there was an observed significant drop in fever pattern (of under-fives) as the level of education of caretakers increase! Thus, while 47 (69.1\%) children who have suffered fever belonged to caretakers with incomplete primary school, only 15 (27.2\%) children with fever were taken care of by individuals 
with secondary level of education.

Also in this survey we assessed the pattern of dental caries among the study sample with the results as shown in the underneath table (in table no. 3):

\section{TABLE 3: THE PATTERN OF DENTAL CARIES} AMONG THE SURVEYED UNDER-FIVES

\begin{tabular}{|l|c|c|}
\hline $\begin{array}{l}\text { DENTAL CARIES } \\
\text { STATUS }\end{array}$ & FREQENCY & PERCENTAGE \\
\hline Present & 3 & 0.75 \\
\hline Absent & 393 & 99.25 \\
\hline Total & 396 & 100.00 \\
\hline
\end{tabular}

Thus from the study, the prevalence rate of dental caries among the surveyed under-fives was found to be $0.75 \%$.

\section{DISCUSSION}

Our study results revealed most of the surveyed under-five population of Dodoma to have been toddlers. The study also revealed male to female ratio of our sample to have been 1:1.01. These observed statistics may be partly used to justify the nature of the study sample. The logic behind domination of toddlers may be the fact that toddlers constitute a significant wider age range than the rest of underfive years population categories (age group: 12-59 months).

We also found that more than half $(51.8 \%)$ of all children surveyed to have been febrile. Since infectious agents are known to be chief culprits in inducing pyrexia in humans, this finding clearly signifies a state of jeopardy among these underfives as far as infectious diseases are concerned. It may also endeavours to justify the existing hypothesis of tropical nations to be endemic for infectious diseases. The above finding is consistent with other studies done in similar environment within the tropics.

One study done in rural Ethiopia in 1997 revealed the prevalence of infections (specifically enteric parasitosis) to be $48.1 \%^{2}$. Tanzania is known to be holoendemic for malaria and since the chief presentation of malaria is fever, it is likely that a significant proportion of this study sample had malaria or had suffered from malaria in the set time period.

However, since our study was cross-sectional in design, no temporal relationship could be elucidated for the possible aetiologies of fever among the surveyed under-fives of this area. Thus an exploratory study (analytical and longitudinal in settings) specifically designed to look on the pattern offever is needed so as to reveal the possible nature and cause(s) of fever among residents of Dodoma.

We also found that almost half (49.3\%) of the study population with fever (at the time of study) had a normal weight to age ratio. This finding has alternative explanations, as perhaps the onset of fever (in this study sample) was acute and followed by immediate interventions that resulted to minimal weight changes among affected children.

Otherwise another possible explanation to this dubious finding could be that most of the surveyed children had an acute fever during the time of the survey and since the survey was cross-sectional in design (exposure status and outcome of interest measured at the same time) the time lap that is necessary for the anticipated changes in weight to age ratio was lacking. Thus while a significant proportion of those children found to have fever could have been due to infections obtained just prior to the execution of the study and they could later on end up being underweight, a time factor was necessary before the observed finding brought the anticipated results in weight for age ratio.

The finding that a more significant proportion (58.8\%) of children were reported to have had fever within a 1-month period prior to execution of the study needs attention in its interpretation. It can signify a proportion of children who had underlying chronic infections to those whose malady subsided in a brief course.

Also since the finding was an assessment obtained usingverbalinformationfromtheparents/guardians (mostly biological mothers); little is known of its validity (however reliable the information was) and hence calls for further interventions.

However, previous studies have shown that validity on interview schedules of under-five years old children morbidity history increases more if mothers are involved than the rest of the family members ${ }^{3,4}$.

In this survey, we also observed the inverse relationship between the level of education of caretakers and the pattern of fever (a reflection of infection??) among the surveyed under-five year population. This finding is consistent with other findings that have been done before to elucidate the relationship between socio-demographic characteristics (such as caretaker level of education) with under-five morbidity patterns $s^{5,6}$. A study done in Tamilnadu, India showed significant differences 
in the pattern of both child morbidity (fever cited as the most important sign) and child malnutrition with low father/mother level of education, where by children with fathers/male guardian with low educational profile were found to be significantly in ill-health than their counterparts whose fathers had a significant higher level of education ${ }^{7}$ Another study done in the Republic of South Africa revealed a positive association between caretaker's low social economic status and the state of malnutrition of the under-five ${ }^{8}$ Thus, when socio-economic status of the caretaker was low, there was also malnutrition and infections among children.

It is no news that poverty is a function of ignorance, and the same vicious cycle applies when one endeavours to explain on the association of infections among under-fives and low socioeconomical status of the caretaker. Several other studies have yielded the same results once a comparison of the caretakers socio-economic status were assessed ${ }^{9,10,11,12}$

Another important finding that we found in this survey was the very low prevalence of dental caries among the surveyed under-five population. This finding has alternative explanations; first, the study sample constituted age groups that are characterised by the pattern of low sugar moments as compared to children at ages 5 12 years, who are most affected by dental caries (secondary to prolonged intake of sugary food stuffs accompanied with poor oral hygiene).

An alternative explanation to this finding may be the fact that majority of the surveyed children were toddlers (with mode age of 14 months and median age group of 12-23 months) and regardless of their sugar moment status, dental caries have not grown to an appreciable extent to be revealed clinically by a mere observation.

\section{CONCLUSION}

The prevalence of fever among under-fives was found to be significantly high in this survey. There was a significant inverse relationship between caretaker's level of education and under-five's pattern of fever. The prevalence of dental caries among under-fives population of Dodoma was very low.

\section{RECOMMENDATIONS}

There is a need for further studies (analytical and longitudinal in settings) to account for the nature, onset and causes of fever in this area.

Continuous public health information is mandatory in this community so as to reduce the burden of infectious disease and childhood malnutrition.

\section{ACKNOWLEDGEMENT}

We would like to extend our appreciation to the Ministry of Higher education, Science and Technology of the United Republic of Tanzania for financial support of this survey.

We are highly indebted to Makulu ward students' group as well as to our supervisor Mr.H.Mohammed of the Dept of community health, SPHSS at MUHAS.

Lastly (but most important), we extend our heartfelt appreciations to all under-five year old children involved in this survey. Our final word to them "Thanks a million!!"

\section{REFERENCES}

1. World Health Organisation (1999). World Annual Health report.

2. Asfaw S.T., Goitom L. (2000) Malnutrition and enteric parasitosis among under-five children in Aynalem village, Tigray. Ethiop. J. Health Dev.14(1):67-75.

3. Kalter H, Gray R, Black R, Gultiano S (1991) Validation of the diagnosis of childhood morbidity using maternal health interviews. Int. J. Epidemiol.; 20(1): 193-8.

4. Rousham E, Northrop-Clewes C, Lunn P. (1998) Maternal report of child illness and the biochemical status of the chilld: use of morbidity interviews in rural Bangladesh. British Journal of Nutrition;80(5): 451-6.

5. Islam MA, Rahman MM, Mahalanabis D. Maternal and socio-economic factors and the risk of severe malnutrition in a child: a case -control study. European Journal of clinical nutrition; 48: 416-424.

6. Rayhan MI, Khan MSH. Factors causing malnutrition among under five children in Bangladesh. Pakistan Journal of Nutrition 2006; 5(6): 558 -562.

7. Bazroy J., Panda P, Purty AJ, Philip B. (2005) Refugees children in India: A comparative study. Hong Kong Journal of Paediatrics (New series); 10:101-108.

8. Zere E, Mc Intyre D. (2003) Inequities in under-five child malnutrition in South Africa. International Journal for Equities in Health;2:7 doi:10.1186/14759276-2-7.

9. Al Mazrou Y, Khan M, Aziz K, Farag M, Al Jefry M. The social factors in the prevalence of diarrhoeal diseases in under-five Saudi children. J Trop Paediatr. 1995; 41 (suppl 1): $45-52$

10. Mikhail B. Hispanic mothers' beliefs and practices regarding selected children's health problems. West J Nurs. Res. 1994; 16(6):623-638.

11. Keith N. Feeding, weaning and diarrhoeal illness in young Hausa children in Niger. PhD Dissertation, Michigan State University, Lansing, MI, 1991.

12. Wamani H, Astrom AN, Peterson S, Tumwine JK, Tylleskar T. Boys are more stunted than girls in subSaharan Africa: a meta-analysis of 16 demographic and health surveys. BMC Paediatrics 2007;7:17. 